Aletria, Belo Horizonte, v. 29, n. 3, p. 347-352, 2019

\title{
WISNIK, José Miguel. Maquinação do mundo: Drummond e a mineração. São Paulo: Companhia das Letras, 2018. 304 p.
}

\section{Marcos Vinícius Scheffel}

Universidade Federal do Rio de Janeiro (UFRJ), Rio de Janeiro, Rio de Janeiro / Brasil marcos.scheffel53@gmail.com

Itabira é apenas uma fotografia na parede, Mas como dói!

Carlos Drummond de Andrade

Lançado em 2018 pela Companhia das Letras, Maquinação do Mundo: Drummond e a Mineração (304 páginas), de José Miguel Wisnik, é um livro que foge a vários cacoetes de uma parte considerável da crítica literária/universitária brasileira. Esses cacoetes poderiam ser assim resumidos: erudição instransponível, direcionamento somente para leitores especialistas em literatura e pouca relevância do tema tratado.

Começando pelo último item, pode-se dizer que os assuntos tratados no livro de Wisnik interessam à sociedade de um modo geral, bastando lembrar do desabamento da barragem da Vale em Mariana, em 10 de dezembro de 2015, com 18 mortos, 1 desaparecido e danos ao Rio Doce, à fauna marítima e à cidade de Mariana e seus moradores. Não bastasse este crime cometido pela Vale, que ainda ecoa na memória de muitos, em 25 de janeiro de 2019, o rompimento da Barragem do Feijão em Brumadinho vitimou mais de três centenas de pessoas, sendo que muitos corpos ainda não foram localizados, causou danos irreversíveis ao Rio Paraopeba e prejuízos econômicos incalculáveis para todas as cidades daquela região.

Mas o que tudo isto tem a ver com literatura? Qual a importância disto para a crítica literária brasileira? A resposta é Carlos Drummond de Andrade, que nasceu em 1902 em Itabira de Mato Dentro/MG que foi 
também o local de instalação em 1942 da Companhia Vale do Rio Doce S.A. Ou Itabira teria sido instalada na Vale? De outra forma: era Itabira que dependia da Vale ou a Vale que dependia de Itabira? Conforme Wisnik citando Drummond: "Contra aqueles que alegavam que ' 70 da população de Itabira vive em função da Cia.', ele [Drummond] contra-argumentava que ' $100 \%$ da Cia. [...] vive em função do ferro de Itabira'."

É a partir de inflexões críticas como esta - espalhadas ao longo de décadas na obra de Drummond - que José Miguel Wisnik procura entender como a história da mineração brasileira/mundial perpassa a obra do maior poeta brasileiro. O poeta obcecado pela palavra "mundo", como registra o crítico, mas também o poeta obcecado por sua pequena cidade de nascimento que figurou em praticamente todos seus livros de crônicas, contos e poemas. Com isso, a tarefa do crítico toma dimensões enormes ao tentar juntar estas duas histórias: a da exploração do minério de ferro, que se liga a todo o desenvolvimento técnico do século XX, e a de como esta exploração ecoou na obra de Drummond, como tudo isto se misturou com uma mitologia pessoal traçada ao longo de sua produção poética e que poderia passar despercebida para quem não conseguisse juntar estas duas histórias:

Trata-se cotejar os desdobramentos históricos com as suas repercussões em prosa e verso, que vão desde a anotação mais fina, a rememoração lírica, a resistência sintomática e a intervenção de protesto até o enigma, a alegoria e a cifra sobre o destino humano. ${ }^{2}$

O próprio crítico esclarece que só conseguiu entender esta dimensão - a da história da mineração em Drummond - quando visitara em julho de 2014 durante o Inverno Cultural de Minas Gerais a cidade natal do poeta. Em Itabira, o crítico pôde ver a cena do crime: a eliminação do Pico do Cauê, que podia ser visto da varanda da casa da infância do poeta - citado no poema $A$ montanha pulverizada (trecho citado abaixo) - e a transferência da Fazenda do Pontal (rememorada em outros poemas de Drummond) para outro local com uma vista privilegiada da destruição causada pela empresa mineradora.

${ }^{1}$ WISNIK. Maquinação do mundo: Drummond e a mineração, p. 154.

${ }^{2}$ WISNIK. Maquinação do mundo: Drummond e a mineração, p. 77-78. 
Foi neste momento que o crítico percebeu que havia algo ainda não compreendido pela crítica brasileira e que o poema Máquina do Mundo, publicado em Claro Enigma (1951), objeto de inúmeras análises ao longo das últimas décadas, tinha muito a dizer para o tempo presente, podendo esclarecer como os crimes de Mariana e Brumadinho não foram apenas "tragédias", mas o resultado de uma ótica capitalista que transforma tudo em estoque: a natureza, o homem, a história, os afetos.

Por esta leitura, o longo poema Máquina do Mundo (96 versos divididos em 32 estrofes) ocupa um lugar de destaque na poética drummondiana e o motivo de o eu lírico recusar, ao final, aquilo que a máquina lhe oferece - objeto de divergência da crítica especializada em Drummond - serviria para interpretar várias questões como, por exemplo, o caráter mais hermético dos poemas de Claro Enigma. O que teria levado o Drummond de Sentimento de Mundo (1940) e de A rosa do povo (1945) a fazer este giro de $360^{\circ}$ - saindo de uma poesia engajada - para uma poesia mais cifrada e, por assim dizer, elitizada? No caso de A máquina do Mundo, o poema traz ecos de Dante Alighieri e Luís de Camões na técnica composicional dos versos e, no plano temático, faz lembrar o pacto fáustico de Goethe. Sobre a longa enumeração dos poderes irrestritos oferecidos pela máquina do mundo ao eu lírico, conclui Wisnik: "Não se trata a meu ver, de uma enumeração abstrata e genérica, mas de uma visão articulada e nítida de um universal concreto, captado em voo rasante até o coração mineral da terra." ${ }^{3}$

Aqui temos aquele momento perigoso em que o excesso de erudição do poema poderia vir acompanhado de comentários do crítico que mais confundissem do que explicassem ao leitor, mas não é o que acontece. Talvez isso se dê pelo desejo de comunicação do crítico e professor com o leitor comum, de partilhar o que sabe de uma forma generosa, de seduzir suas audiências. Elementos que José Miguel Wisnik pôde testar em outubro de 2016 em palestra ministrada no Instituto Moreira Salles do Rio de Janeiro no evento intitulado "Dia D" ou então ao publicar um trecho do seu trabalho na Revista Piaui (n. 142, de julho de 2018, p. 50-55). Este desejo de se comunicar com um público mais amplo também foi verbalizado em um curso de três dias ministrado em fevereiro de 2019 na Casa de Rui Barbosa. Nas palavras iniciais do curso,

${ }^{3}$ WISNIK. Maquinação do mundo: Drummond e a mineração, p. 214. 
Wisnik frisou que o pesquisador universitário deve ter esta capacidade de não falar apenas com seus pares, mas à sociedade de um modo geral.

Destaque-se que este desejo de comunicação não gera um rebaixamento do texto do autor ou uma facilitação dos temas, mas apenas um direcionamento que prevê leitores diferentes. O leitor comum poderá entender melhor os mecanismos críticos do maior poeta brasileiro. As reações de Drummond a fatos que lhe interessavam diretamente e como tudo isto de certa forma tomou corpo em sua poesia. Este leitor com certeza se sentirá em vários momentos convidado a reler Drummond ou a lê-lo por uma primeira vez. Isto por que as análises de Wisnik - não só de a Máquina do Mundo, como a de todos os outros poemas que tocam no tema - são uma verdadeira lição de como ler a poesia sem limitar seus sentidos, apontando os temas que ressoam na obra: Como tenho dito, vida e obra de Carlos Drummond de Andrade (1902-1987) correm em paralelo com os desdobramentos da mineração em Itabira, indo da potência indomável do Cauê quase virginal ("a boca da mina, lá longe, pequena mancha preta no dorso cinza-roxo da montanha") até a entronização engolidora do aparato técnico explorador que consolida o protagonismo da Companhia Vale do Rio Doce. ${ }^{4}$

Já o leitor com um perfil mais acadêmico é também contemplado: com o escopo crítico rigoroso (Walter Benjamin, Giorgio Agamben, Max Korkheimer, Martin Heidegger, Henri Bergson); com a revisão da fortuna crítica de Drummond (José Guilherme Merquior, Silviano Santiago, Alcides Villaça); com a divulgação de trabalhos mais recente sobre o poeta (Murilo Marcondes e Ivan Marques); com a conexão do poema de Drummond com a produção de autores do plano internacional (Franz Kafka, Herman Melville e Jorge Luís Borges); com a ligação a temas multidisciplinares (ecologia, economia, história, política).

Ainda neste viés mais acadêmico aparece a contestação das leituras promovidas por Sérgio Miceli em "Intelectuais e classes dirigentes no Brasil (1920-1945)", em que o sociólogo procurava demonstrar como os intelectuais brasileiros deste período, oriundos de famílias rurais decadentes, teriam se favorecido com o Estado Novo getulista. Para Wisnik, estas críticas construídas a partir dos poemas em que Drummond retoma sua história familiar não procedem por um simples fato: é o próprio Drummond que a todo momento questiona seu lugar no mundo,

\footnotetext{
${ }^{4}$ WISNIK. Maquinação do mundo: Drummond e a mineração, p. 115.
} 
sua história familiar, relembra as relações autoritárias da época da escola, questiona o mandonismo de seus antepassados, questiona abertamente seu lugar de intelectual dependente até certo ponto do Estado, mas que nunca deixou de fazer as críticas necessárias aos mecanismos poderosos - como, por exemplo, a Companhia Vale do Rio Doce. Este lugar de fala é posto em cena pelo poeta a toda hora de uma forma complexa, como se pode ver no conhecido poema Confidencia do Itabirano, publicado em Sentimento do mundo, que empresta epígrafe para esta resenha.

A retomada dos assuntos tratados na obra é fácil por conta de um índice remissivo com o nome de pessoas citadas, críticos, poemas analisados. A dedicatória inicial do livro é muito significativa por mostrar as várias pessoas que contribuíram para obra: responsáveis por acervos, amigos do meio acadêmico de outras áreas, colegas de trabalho que tiveram a oportunidade de ler ou ouvir o trabalho. Tudo isto mostra o movimento dialógico do crítico, numa postura de não se isolar no silêncio de seu gabinete. Algo que acaba sendo coerente com a própria trajetória de Drummond.

A edição traz ainda um impactante registro fotográfico com imagens de época de Itabira, revelando paisagens que não existem mais, como o Pico do Cauê, explorado até virar uma cratera; o sobrado da família de Drummond - construído para "Ter vista da serra / de poder a poder" 5 e que hoje mira o vazio deixado pela Vale; a igreja do Rosário, que tombou em 1970, ao que tudo indica, pelas explosões para extração do minério de ferro promovidas pela Vale do Rio Doce; e uma propaganda da Vale de 20 de novembro de 1970, que promove um curioso diálogo com o poema No meio do caminho.

Itabira, Mariana e Brumadinho são muito mais que fotos/imagens/ notícias que trazem uma história dolorosa do passado recente do Brasil. José Miguel Wisnik, valendo-se da potência poética de Drummond, mostra como este conviveu "surdamente com as tramas das maquinações minerais que se desenrolam no país ao longo do século XX". ${ }^{6}$

\footnotetext{
${ }^{5}$ ANDRADE. Boitempo: menino antigo, p. 87.

${ }^{6}$ WISNIK. Maquinação do mundo: Drummond e a mineração, p. 77.
} 


\section{Referências}

ANDRADE, Carlos Drummond de. Boitempo: menino antigo. Posfácio de Jonh Gledson. São Paulo: Companhia das Letras, 2017.

WISNIK, José Miguel. Maquinação do mundo: Drummond e a mineração.

São Paulo: Companhia das Letras, 2018. 304 p. 